\title{
To replace or not to replace mild to moderately dilated sinuses of Valsalva: When less is more
}

\author{
Christopher M. Feindel, MD, MSc, and Maral Ouzounian, MD, PhD
}

\footnotetext{
From the Division of Cardiovascular Surgery, Peter Munk Cardiac Centre, Toronto General Hospital; and the Department of Surgery, University of Toronto, Toronto, Ontario, Canada. Disclosures: Authors have nothing to disclose with regard to commercial support.

Received for publication April 16, 2017; accepted for publication April 21, 2017; available ahead of print May 23, 2017.

Address for reprints: Christopher M. Feindel, MD, MSc, Peter Munk Cardiac Centre, 200 Elizabeth St, 4N-480, Toronto, Ontario M5G 2C4, Canada (E-mail: Chris.feindel@uhn.ca).

J Thorac Cardiovasc Surg 2017;154:433-4 $0022-5223 / \$ 36.00$

Copyright (C) 2017 by The American Association for Thoracic Surgery http://dx.doi.org/10.1016/j.jtcvs.2017.04.049
}

Patients undergoing aortic valve surgery often have some degree of aortopathy. In this era of ubiquitous imaging, surgeons generally have detailed preoperative measurements of the proximal aorta. The ultimate decision, however, regarding how much aorta to resect is made under direct vision. Not infrequently, in addition to a diseased aortic valve and ascending aneurysm, there is only mild to moderate dilatation of the aortic root. Surgeons have tended to be more aggressive in replacing the root in patients with a bicuspid valve because of the theoretic risk of root aneurysm formation or of a catastrophic dissection involving the aortic sinuses.

In reaching a decision as to how best to manage the mildly dilated aortic root, the surgeon will ask the following questions: How old is this patient? How significant is the root dilatation? Is only one sinus involved? Are the coronary ostia displaced cephalad? What is the quality of the aortic tissue? Is this patient likely to require open reoperative surgery or transcatheter aortic valve intervention in the future? Does this patient wish to receive a biologic or mechanical valve? Am I comfortable doing a Bentall procedure on this patient? Does this patient also require coronary artery bypass grafting surgery or concomitant complex arch reconstruction? Is this patient otherwise healthy? What are the chances that the mildly dilated sinuses of Valsalva will progressively enlarge? It is this last question that Mlewski and colleagues ${ }^{1}$ from the University of Pennsylvania have attempted to answer in this issue of the Journal.

Mlewski and colleagues ${ }^{1}$ reviewed 428 patients who underwent aortic valve plus supracoronary ascending aortic replacement. Patients were stratified according to valve morphology (tricuspid vs bicuspid), pathology (stenosis v. insufficiency), and sinus of Valsalva (SOV) dimensions ( $<40 \mathrm{~mm}$ vs $40-45 \mathrm{~mm}$ vs $>45 \mathrm{~mm}$ ), although in more than $90 \%$ of cases, SOV size was smaller than $45 \mathrm{~mm}$. A useful surgical algorithm was provided, although, as in all retrospective studies, surgeon judgment was not quantified. For example, few patients with

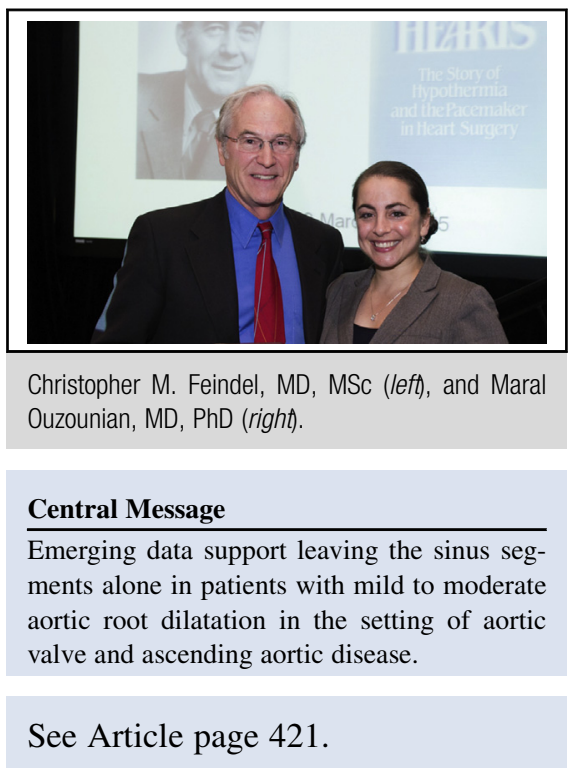

bileaflet aortic valve and SOV larger than $45 \mathrm{~mm}$ were included, suggesting that surgeons were reluctant to leave the sinus segments intact in this group. Early outcomes were excellent, and aortic sinuses remained stable in all groups through a mean follow-up of 43.5 months. In the very few cases that required reoperation, none were for progressive SOV dilatation. Despite the relatively short follow-up, the minimal and nonsignificant changes in root dimensions suggest that the remnant SOV will likely remain stable in the long term, thus supporting a conservative approach to the management of the mild to moderately dilated root.

Are these results sufficient to convince surgeons that they need not worry about the sinuses of Valsalva in these patients? A recent publication of Peterss and colleagues $^{2}$ from Yale came to the same conclusion after observing very slow growth of the aortic root in 102 patients during the course of 6 years regardless of whether the aortic valve was replaced. Peterss and colleagues ${ }^{2}$ predicted that patients with preoperative root dimensions smaller than $45 \mathrm{~mm}$ would require 29 years to reach $50 \mathrm{~mm}$, a time frame that would only be of significance for young patients. These emerging data should put to rest concerns about leaving the mildly dilated aortic root intact. It is important to note that these observations do not apply to patients with genetically triggered aortopathies, who require a more aggressive approach to root aneurysms. 


\section{References}

1. Mlewski RK, Habertheurer A, Bavaria JE, Siki M, Szeto WY, Krause E, et al. Fate of remnant sinuses of Valsalva in patients with bicuspid and trileaflet valves undergoing aortic valve, ascending aorta, and aortic arch replacement. J Thorac Cardiovasc Surg. 2017;154:421-32.
2. Peterss S, Bhandari R, Rizzo JA, Fang H, Kuzmik GA, Ziganshin BA, et al. The aortic root: natural history after root-sparing ascending aortic replacement in nonsyndromic patients. Ann Thorac Surg. 2017;103: 828-33. 